is aggravated by the subsequent statement made at the last meeting of the Society that the case had been in the law courts, and was a cause célebre. There is not a shadow of truth in this cruel calumny. It never was in any law court.

At page 294 of your current volume, it is stated in the report of a lecture delivered at Glasgow that I, who may be said to have been one of the earliest advocates of ex. ploratory incisions, disconntenance them becanse a young lady is said to have been brought to me in 1884 by her medical attendant (who is not named), and that I then dis. couraged operation. The tumour I then found is said to have increased afterwards, and to have been removed last year. It is not stated whether I saw the patient or not after 1884. If I knew the name of the surgeon who is said to have brought her to me, it is not at all improbable that the inaccuracy in the statements of the case brought before the Gynæcological Society would be equalled in the statement of the case of this young lady; and that the whole story, if not essentially fabulous, would still prove to be exactly such a "truth which is half a truth," as Tennyson has stigmatised in immortal verse.

I am, Sirs, yours truly,

Upper Grosvenor-street, Feb. 10th, 1891. T. SPENCER WELLS.

* * This correspondence must now cease. We cannot afford further space for the prolongation of this unfortunate controversy.-ED. L.

\section{INSURANCES ON THE LIVES OF PHYSICIANS.}

\section{To the Editors of THE LANCET.}

SIRS,-Some time ago Mr. James Chatham addressed a letter to THE LANCET, in which he showed that the mortality among medical men was far in excess of the expected number, as calculated by the Actuaries' Healthy Males Table. He took his data from the census returns of 1861 . 1871, and 1881. His conclusions I by no means desire to call in question. They serve very pointedly to indicate in a sufficiently telling manner the sacrifices, even of life itself, which medical men are daily called upon to make, and which they cheerfully make, for the welfare of their fellow-men. But, from a life assurance point of view, it appears to me that this method of calculating the value of the life of a medical man is hardly a fair one; for it must be remembered that the mortality rate which Mr. Chatham worked out is obtained from the deaths of all medical men in the United Kingdom, at all ages, assured and non-assured. Now, it is well known that many of these die quite young, before they attain the average age at which medical men think itnecessary toassure their lives, by reason of the peculiar risks and hardships to which their calling subjects them. Further, in common with all who desire to assure their lives, medical men have to submit to a thorough medical examination, and thus the unhealthy are excluded, and the company assuring them has to deal with selected risks who will be much more likely to fulfil their expectation of life than the general body of medical men. To some extent this is borne out by the investigation of the mortality statistics of the Scottish Widows' Fund and Life Assurance Society, on which I am at present engaged. The period extends over fourteen years, and the number of claims amounts to 5505 . Of these, 248 are made by the representatives of medical men. (Under this heading I class physicians, surgeons, and dentists.) The average age at which they assured their lives was thirty.five, and their average age at death was fifty-six in round numbers. Their expectation, according to the Actuaries' Heal thy'Males Table, was thirty-one years, and of this they fulfilled, on the average, twenty-one years. Now, the average duration of the whole 5505 was only 20.790 years, in round numbers twenty. one years; and the average age at death of the total number was 57.633 . It would thus appear that medical men are quite up to the average of assured lives in fulfilling their expectation of life. A further examination brings out the fact that they are a better class of lives than shopkeepers, engineers, architects, teachers, artists, and much better than bakers, butchers, masons, commercial travellers, clerks, and bookkeepers. Mr. Chatham showed that the lives of medical men, in the whole country, were shorter than those of coalminers. But, from the example I have been able to adduce, this does not seem to hold good for selected lives.
It may not be without interest to some of your readers to learn what are the principal disorders by which medical men are cut olf". In common with other members of the Suciety, a large percentage die of heart disense and diseases of the nervous system. Bat, as might almost have been predicated, a large number succumb to pneumonia; nearly double the number died of this disease as contrasted witl the other insurers. The same remark applies to enteric fever and other zymotic diseases, while more than the average come to an untimely end by violent or sudder death. These causes are manifestly incidental to their calling, and probably cannot be well guarded against. On the other hand, it is curious to pote that consumption claims as its victions only about one-third of the total average of deaths from this cause, and no less than thirteen attained the venerable average age of eighty-four, and were justifi. ably classed as dying of "old age."

I am, Sirs, yours faithfully,

Edinburgh, Feb. 10th, 1891. Cladd MuImIEad, M.D.

\section{DR. KOCH'S FLUID.}

\section{To the Editors of THE LANCET.}

Srrs,-In connexion with the action of Dr. Koch's fluia on lupus would you allow me to call attention to Dr。 Fehleisen's experiments with pure cultivations of the micrococcus of erysipelas on this disease, to which I have not noticed any reference in discussions on the subject. The translation of Dr. Fehleisen's paper appears in the Sydenham Society's volume, "Micro-parasites in Disease," published in 1886 . On page 272 of this volume, speaking of the curative effect of erysipelas, he says: "I shall also. omit the descriptions of its curative effect in chronic joint affections and different forms of syphilis, al though particularly in connexion with the latter many reliable accounts exist. The curative effects on lupus are, however, welk guaranteed by a number of trustworthy and experienced observers, of whom I need only mention Helva." Further on, page 278 , he gives the result of an inoculation in these words: "In order to exclude the objection that the cultivation was dead, a fifth patient, a girl twenty-nine years old, who was suffering from an extensive lupus of the face, was at the same time inoculated with the rest of the same cultivation. She had also recovered from erysipelas of the face in Dec. 1881. The rigor appeared forty-seven hours after inoculation, the temperature rose at once to $39.5^{\circ} \mathrm{C}$, and reached the same day $40.1^{\circ} \mathrm{C}$., and on Oct. 28 th (i.e., four days after inoculation) it became normal. The disturbance of general health was in this case very marked. The short duration of the attack may be accounted for by the fact that the patient had had an attack of erysipelas of the same place ten montlis previously. The lupus healed as the result of the erysipelas with the exception of a few nodules in the neighbourhood of the nostrils." Dr. Fehleisen's paper and experiments open up many questions of deep. interest to the profession into which I shall not now enter. In connexion with Dr. Koch's fluid they raise the questions whether the action of this fluid on lupus (and possibly in chronic joint affections) has any specific relation to the tubercle bacillus from cultivations of which it is said to be produced.

Exeter, Feb. 9th, 1891.

I am, Sirs, yours truly, HENRY DAVY.

\section{A PLEA FOR LIBERTY.}

To the Editors of THE LANCET.

SIRs, - In the introduction to a collection of essays lately published, and entitled "A Plea for Liberty," Mr. Herbert" Spencer हays: "The root of all well-ordered social action is a sentiment of justice, which at once insists on personal freedom, and is solicitous for the like freedom of others, and there at present exists but a very inadequate amount of this sentiment."

In ancient Egypt, as Herodotus tells us (II. 81), the art. of healing was distributed into several departments, each practitioner occupying himself with a single disorder, and no more. This subdivision, maintained from generation to generation, did, no doubt, for a tine favour the attainment. of personal knowledge and skill, but, by persistently con. tracting the intellectual sympathies, and circumscribing the range of observation, it ultimately defeated its own end. There was, however, a more pernicious influence at 
work. Under the tyrannical sway of the priest-physicians, every medical man was, according to Diodorus Siculus (I. 82), obliged to apply his remedies in conformity with rules laid down in certain books deemed sacred. If his patient died he was freed from blame, provided he had observed these rules, but if he had not, he was tried for his life. With precept and practice both penally prescribed, independent research and free inquiry were impossible; and it is not surprising, in spite of Homer's praise of Egyptian physicians as "skilled beyond all human kind," that theoretic medicine made so little progress.

Considering the temper and bearing of some of the socalled leaders of our profession, and the tone of several of the controversies that have of late been carried on in your columns, can we say that the spirit which animated the sacerdotal caste of ancient Egypt is yet extinct?

Feb. 7th, 1891 . I am, Sirs, yours truly, JoHN TweEdr.

\section{ON THE OPERATIVE TREATMENT OF DISEASE OF THE UTERINE APPENDAGES. To the Editors of THE LANCET.}

SIRs,-Few things could be more personally distasteful to me than to find myself differing strongly in opinion from Dr. John Williams and Dr. Champneys. On this occasion, however, I should be false to my convictions if I did not express $m y$ dissent from their view. I deprecate as strongly as they the removal of healthy ovaries, whether ill developed or otherwise, simply for the relief of pain. The question on which we differ is the proportion of cases of actual disease of the appendages in which, "on ordinary surgical principles," operative interference is called for. "I Welieve this proportion to be much larger than they seem prepared to admit. In a paper published five years ago ${ }^{1} I$ wrote as follows: "I have now for some time been con. vinced that surgical interference affords us the best, if not the only, means at our disposal of relieving and curing a ilarge number of women who have hitherto drifted on from year to year without sensible amelioration of their suffering, and who have long been the opprobria of our gynæcological out-patient and consulting rooms." This conviction, slowly and reluctantly arrived at, increased experience has but served to deepen. I hope before very long to bring before the Obstetrical Society the evidence furnished by my own cases. I shall then be prepared to discuss the subject fully, and to state the grounds on which my opinion and practice are based. I am, Sirs, yours faithfully,

Brook-street, W., Feb. 9th, 1891. Chas, J. Cullixgworth.

\section{To the Editors of THE LANCET.}

SIRs,-Certain statements contained in the joint letter of Drs. John Williams and Champneys in your issue of Feb. 7 th seem so widely at variance with the teaching of other gynæcologists that those who are still open to conviction, and desire to ascertain which creed is the true one, must be excused if they venture to seek for fuller information than the letter gives. Is it permissible to ask the authors of the letter to fulfil the same obligations to the profession as they require from those who differ from themviz., (1) to state the number of women seen during the periods they refer to a little more exactly than by "thousands," and (2) the proportion of "tubal" cases among them. Further, it would be highly valuable to learn what proportion of cases of pyo-salpinx or suppurating ovary, or of tubercular, tubal, or ovarian disease, has been cured by patience? What is the average duration of such cases when treated by patience? How long is pelvic suppuration to be left uninterfered with after diagnosis and treated with patience? Is "patience" synonymous for purely expectant treatment, or what is meant? "Patience and resignation will lighten every difficulty," but it is just as true non est vivere sod valere vita. Will the authors formulate some more definite and precise rules for general guidance as to when it is "imperative to operate," when advisable? Such great advances have been made within the last ten years in cerebral, renal, hepatic, and splenic surgery, that one cannot help feeling that pelvic surgery also may be improved by a fair and exhaustive discussion without regard for aught but the best interests of humanity. Pluris -est oculatus testis unus quam auriti decem. Five years ago
I was prejudiced against tubal operations ; since then, and particularly within the last year or two. I have seen a considerable number of such operations. The result has been that in practically every instance the pathological condition has amply proved the absolute necessity for surgical interference. I I Grosvenor-street, w., Feb. 9th, 1891. A. D. LEITH NAPIER.

\section{To the Editors of THE LANCET.}

Sirs,-In Trie LANCET of Jan. 17th (p. 145) my own opinions upon this subject will be found expressed in the summary of my paper, which was read in conjunction with Dr. William Duncan's. The moral that I nieant to draw was more extreme than any included in the manifesto of two distinguished London obstetricians ${ }^{1}$ and in a letter from a colleague. ${ }^{2}$ Let readers of papers beware how they advocate the removal of appendages for chronic inflamma. tion. Such is the warning note sounded by Drs. John Williams and Champneys. Let readers of papers beware how they advocate any active treatment of appendages affected with chronic inflammatory disease, say I. If an experienced operator writes about "successful cases" of oöphorectomy - which means cases that have recovered from the operation-only too many inexperienced men will be tempted to operate. We must beware, however, how we deprecate operations, for, unless we express what we mean very accurately, we may be misunderstood. I trust, Sirs, that in my paper I made myself clear. In warning men against abdominal section for the class of disease in question we must, as a bounden duty, remind them that unlimited "minor gynacology" is yet more unjustifiable. For the inexperienced are easily dissuaded trom operating; unfortunately they are apt to think that "minor" proceedings are safe and justifiable. Dilatation of the cervix and scraping, valuable in pure endometritis, are fascinating to the practitioner who may dread to open the abdominal cavity. Nevertheless, I know that " curettage " may cause even worse results than injudicious oöphorectomy. In short, I fear, or rather I know, that there is not only too much oöphorectomy, but also too much active treatment of chronic disease of the appendages by the curette and other appliances. Not only do I go furtber than the distinguished authors of the manifesto, but I also go as far if not further than my colleague. Mr. Meredith shows that but few oöphorectomies for chronic disease are performed at the Samaritan Free Hospital, where there is much operating for the removal of tumours. Dr. Cullingworth, in reply to my colleague, ${ }^{3}$ remarks that at the Samaritan Hospital we receive an over. whelming proportion of abdominal tumours. On the other hand, at the general hospitals "cases of pelvic inflammation, due to or complicated by Fallopian tube disease, are ad. mitted $(s i c)$ in at least equal proportion with cases of ovarian tumour." Dr. Cullingworth is labouring under a false im. pression, unless we dwell strongly on the word " admitted." The truth is that in the out-patient department of the Samaritan Hospital hardly a day goes by without cases of chronic disease of the appendages applying for relief. On the other hand, many weeks of ten pass witbout a single case of true ovarian tumour being seen. Mr. Meredith and myself have had ample opportunities for gaining experience of chronic disease of the appendages. We happen, however, to be in accord with the authors of the manifesto. We might admit many of these cases, until the number of oöphorectomies greatly exceeded the ovariotomies. We act otherwise, however, as we find that many cases of chronic disease get well when treated as out-patients. Some obstinate cases recover when admitted into the physicians' wards. There remains a "submerged tenth," as I may call it, where we consider that the sufferings of the patient "call for surgical procedures," as the authors of the manifesto say. My opinion as to the conditions which justify operation is expressed in my paper. - I am, Sirs, yours faithfully,

Granville place, Portman-square, Feb. 9th, 1891. Alban Doran.

\section{To the Editors of THE LANCET.}

SIns,--Holding such strong opinions on the above subject as apparently Drs. Williams and Champneys do, if we may judge from their joint letter which appears in THE LANCET 